\section{Список литературы и источников}

1.Государственный архив Алтайского края. Ф. P1198.

2. Алтайская краевая детская библиотека им. Н. К. Крупской : [сайт]. [Барнаул, -2020]. URL: http://www.akdb22.ru/ (22.11.2020).

3. Ежегодный отчёт о работе краевого государственного казённого учреждения «Алтайская краевая детская библиотека им. Н. К. Крупской» за 2010 г. Барнаул, 2009.

4. Ежегодный отчёт о работе краевого государственного казённого учреждения «Алтайская краевая детская библиотека им. Н. К. Крупской» за 2011 г. Барнаул, 2010.

5. Ежегодный отчёт о работе краевого государственного казённого учреждения «Алтайская краевая детская библиотека им. Н. К. Крупской» за 2012 г. Барнаул, 2011.

6. Ежегодный отчёт о работе краевого государственного казённого учреждения «Алтайская краевая детская библиотека им. Н. К. Крупской» за 2013 г. Барнаул, 2012.

7. Ежегодный отчёт о работе краевого госу- дарственного казённого учреждения «Алтайская краевая детская библиотека им. Н. К. Крупской» за 2014 г. Барнаул, 2013.

8. Ежегодный отчёт о работе краевого государственного казённого учреждения «Алтайская краевая детская библиотека им. Н. К. Крупской» за 2015 г. Барнаул, 2014.

9. Ежегодный отчёт о работе краевого государственного казённого учреждения «Алтайская краевая детская библиотека им. Н. К. Крупской» за 2016 г. Барнаул, 2015.

10. Ежегодный отчёт о работе краевого государственного казённого учреждения «Алтайская краевая детская библиотека им. Н. К. Крупской» за 2017 г. Барнаул, 20016

11. Ежегодный отчёт о работе краевого государственного казённого учреждения «Алтайская краевая детская библиотека им. Н. К. Крупской» за 2018 г. БарнаулБ, 2017.

12. Ежегодный отчёт о работе краевого государственного казённого учреждения «Алтайская краевая детская библиотека им. Н. К. Крупской» за 2019 г. Барнаул, 2018.

\title{
РАСШИРЕНИЕ СПЕКТРА АДАПТИВНЫХ УСЛУГ ДЛЯ ПОЛЬЗОВАТЕЛЕЙ С ОГРАНИЧЕННЫМИ ВОЗМОЖНОСТЯМИ ЗДОРОВЬЯ В АЛТАЙСКОЙ КРАЕВОЙ СПЕЦИАЛЬНОЙ БИБЛИОТЕКЕ ДЛЯ НЕЗРЯЧИХ И СЛАБОВИДЯЩИХ
}

Аннотация. В статье приводится опыт работы Алтайской краевой специальной библиотеки для незрячих и слабовидящих с людьми с ограниченными возможностями здоровья. Охарактеризованы современные формы и методы предоставления библиотечно-информационных услуг, раскрываются качественно новые возможности библиотечно-информационного обслуживания пользователей с ограниченными возможностями здоровья, обусловленные распространением цифровых технологий.

Ключевые слова: люди с ограниченными возможностями здоровья, маломобильнье пользователи, слепье и слабовидящие, специиальная библиотека, циифровизация, библиотечно-информационные технологии.

Сегодня трудно представить библиотеку, которая занимается только выдачей книг. Глобализация, информатизация, развитие современных адаптивных технологий, в том числе для инвалидов и маломобильных пользователей, требуют от библиотечных специалистов внедрения инноваций в формы и методы работы, переустройства внутреннего пространства учреждений, постоянного повышения квалификации, внедрения новых профессиональных стандартов.

Созданная в 1953 году Алтайская краевая специальная библиотека для незрячих и слабовидящих первоначально располагалась на площади 18 кв. м. и оказывала библиотечные услуги незрячим города Барнаула. Ее фонды состояли из изданий рельефно-точечного шрифта. С увеличением 
площадей началось создание передвижных библиотек. В 1962 году впервые поступили «говорящие» книги на рулонах, а в 1965 библиотека получила статус краевой. Переезд в новое помещение по адресу Челюскинцев, 80 позволил увеличить фонд библиотеки и оборудовать лингофонные места для прослушивания «говорящих» книг. В 1974 году открылись филиалы специальной библиотеки в городах Бийск и Рубцовск. В следующем году библиотека значительно расширила свои площади, получив дополнительное помещение по адресу ул. Папанинцев, 205, и начала записывать «говорящие» книги алтайских писателей на кассеты. В 1996 библиотека была переименована в Алтайскую краевую специальную библиотеку для незрячих и слабовидящих.

Как изменилась библиотека с начала 2000 года? Как она видится современным читателям и библиотечным работникам? Нужна ли вообще библиотека в век цифровизации, когда появилась возможность получить книгу дистанционно?

Сегодня специальная библиотека - это центр безбарьерной среды, где архитектурная доступность одно из главный условий её функционирования: тактильная разметка на входе в здание, наличие пандуса, поручни внутри здания вдоль пути следования читателя к месту получения услуги, отсутствие порогов, оборудованная санитарная комната, тактильные информационные таблички и мнемосхемы, сменное кресло-коляска для пользователей и многое другое [1].

В здании учреждения к услугам читателей современное оборудование - тифлофлэшплееры, персональные компьютеры с говорящей программой и выходом в интернет, брайлевские дисплеи, стационарные и переносные электронные лупы, принтер для печати рельефно-точечным шрифтом [2].

В такой библиотеке пользователь с ограниченными возможностями здоровья чувствует себя свободно и уютно. Тем более, что многолетний опыт работы обеспечивает комфортную психологическую среду. Осталось решить вопрос с отсутствием городской инфраструктуры, которая обеспечила бы таким людям комфортное передвижение к библиотеке.

На начало 2020 года пользователями библиотеки являются около 4000 читателей с различными заболеваниями, нуждающиеся в специализированном библиотечно-информационном обслуживании. Наибольшее количество (около 2500 человек) составляют слепые и слабовидящие пользователи, требующие специальных форматов чтения. Значительную долю (более 600 че- ловек) - люди с нарушением слуха. Остальное количество - это инвалиды других категорий, родители детей-инвалидов, специалисты, работающие с инвалидами и жители микрорайона.

В начале 90-х годов свыше 600 пользователей являлись читателями изданий рельефноточечного шрифта. Сегодня число грамотных по системе Брайля составляет чуть меньше 200, а читают по данной системе около 100 человек. В фонде библиотеки состоит 17021 единица хранения изданий данного формата, из них выдается 23 \%. И эта цифра ежегодно падает. В чем причина? Опять же в новых современных технологиях: не нужно изучать шрифт, транспортировать объемные комплекты книг. Комфорт и удобство в переноске, отличное звучание стали основными причинами перехода читателей Алтайского края на книги, записанные на флеш-носители.

Безвозвратно уходят в прошлое издания на магнитной ленте, фонд которых начал формироваться в 1980 году. Из 42000 кассет на конец 2019 года используется лишь 52 \% читателей старшего поколения за пределами регионального центра. Недостатки данного носителя очевидны: магнитная пленка легко заматывается в магнитофоне и рвется, от многократного использования портится звучание. Тифломагнитофоны данной марки для прослушивания аудиокниг не выпускаются, а завод, изготавливающий магнитную пленку, прекратил свою деятельность. Таким образом, реставрировать книгу не представляется возможным. В настоящее время идет поэтапное списание изданий данного формата чтения.

Электронные документы на $\mathrm{CD}$, которые в начале 2000 годов вошли в оборот, особенно в специальных библиотеках, сегодня также претерпевают изменения. Значительное время Алтайская краевая специальная библиотека самостоятельно делала тираж данных аудиокниг, чтобы удовлетворить массовые потребности своих пользователей на территории Алтайского края. В 2019 году из 28234 изданий выдано 9742 (35\%). Накладывает отпечаток закон об авторских правах, который предписывает использование информации на данном носителе только в стенах библиотеки, что мало приемлемо для людей с проблемами здоровья, которым очень трудно находится продолжительное количество времени в библиотеке. В ближайшей перспективе планируется оставить лишь 1 экземпляр данного формата.

Значительный интерес у детской аудитории вызывает фонд рукодельных книг (50 наименований) со съемными элементами, вставками из различных материалов, с вырубками, игровыми и звуковыми фрагментами. 
Главенствующую позицию заняли флэшносители, в том числе за пределами регионального центра (выдача ведется в 18 библиотечных пунктах из 38). Звуковые файлы в формате LKF выдаются из фонда на физических носителях, или записываются сотрудниками учреждения на личные флэш-карты пользователей из электронной цифровой библиотеки. Выдача изданий из цифровой библиотеки в 2019 году составила свыше 15000 единиц.

В стенах библиотеки, или не выходя из дома, незрячие пользователи по логину и паролю могут самостоятельно скачать понравившуюся аудиокнигу с удаленного ресурса «Логос» [3]. В 2019 году читателями ресурса стали 137 незрячих, им выдано свыше 22000 единиц хранения в формате LKF. Количество посещений в удаленном режиме ежегодно прирастает: в 2019 году они составили 5705, в 2018 году - 3804 единиц.

Кроме того, в 2019 году на ресурсе онлайнбиблиотеки «Логос» был открыт удаленный читальный зал Алтайской краевой специальной библиотеки для незрячих и слабовидящих, где были размещены аудиокниги алтайских авторов в количестве 60 экземпляров. В 2020 году он продолжает пополняться. Данные издания записываются непосредственно в студии звукозаписи учреждения. К озвучиванию привлекаются лучшие дикторы Алтайского края - актеры театров, известные теле- и радиоведущие с хорошо поставленными голосами, авторы произведений. Особое место уделяется издательским проектам, направленным на продвижение книг в среду людей с нарушением здоровья, посвященные известным людям края: В. Шукшину, В. Золотухину, Г. Титову, Р. Рождественскому.

Расширение цифрового пространства требует и от сотрудников библиотеки, и от пользователей освоения новых технологий, которые позволяют сделать книгу доступной для скачивания на айфоны, андроиды, тифлофлэшплееры различных марок, персональные компьютеры. Поэтому библиотечные работники постоянно оказывают консультационную помощь инвалидам в освоении новых технических продуктов.

Свободный доступ в помещении библиотеки предоставляется к ресурсам Национальной электронной библиотеки (НЭБ) и ЛитРес. Но создает множество проблем для читателей с нарушением зрения, которые предпочитают звуковой формат чтения: сложность системы поиска в общем массиве, ограниченность наименований и выдачи по тематике, отставание по репродуцированию изданий в звуковую форму. Важно еще учесть такой аспект, как способ прослушивания данных изда- ний на оборудовании. В настоящее время по индивидуальной программе реабилитации инвалидам по зрению бесплатно выдаются аппараты с криптозащитой. Поэтому приходится осваивать и оборудование с прослушиванием в формате МР 3 и LKF. А для слепого человека - это хоть и временная, но проблема.

Новым вектором расширения спектра услуг стало поддержание и ведение сайта, с учетом особенностей восприятия текстовой, графической и звуковой информации инвалидами по зрению и слуху. Это позволяет, например, записаться в библиотеку, заполнив электронный формуляр, не выходя из дома, или выбрать книгу из электронного каталога. А индивидуальное информирование, в таком случае, можно осуществлять еще и по электронной почте, что очень удобно для людей с нарушением здоровья. И для родителей детей-инвалидов, которые очень загружены, открываются новые возможности.

Возросла роль социальных сетей, направленных на различные задачи, например, групповое информирование пользователей, привлечение к участию в конкурсах и проектах, аудиозанятия и видеотрансляции, в том числе с сурдопереводом и другие возможности.

Конечно, кроме востребованного фонда и элементов доступности, значительным фактором притяжения пользователей в библиотеку является культурно-просветительская деятельность, интеллектуальное чтение, создание мест комфортного общения.

Из наблюдений, опросов, бесед с читателями давно стало понятно, что необходимо отказаться от традиционного разграничения пространства. При этом зонирование пространства очень сложно осуществить на ограниченных площадях библиотеки, с учетом интересов и физиологических потребностей пользователей. Таких, как совместное нахождение незрячих, которые воспринимают информацию на слух, и людей с нарушением слуха, которые могут непроизвольно издавать громкие звуки.

Наш читальный зал - это свободная зона, где можно отдохнуть с книгой в руках или послушать ее на тифлофлэшплеере, посидеть за компьютером, воспользоваться лупой, это место проведения множества различных интересных мероприятий, а книги, журналы и газеты уже сегодня выдаются на дом читателям, здесь можно сыграть в шашки или шахматы. Но как все это уместить на 100 квадратных метрах? Пока мы делаем первые шаги к зонированию пространства. Современный дизайн, новые стеллажи, мягкая мебель, специализированное оборудование - необходи- 
Культура в евразийском пространстве: традиции и новащчии. № 1 (4) 2020 2.

мые составляющие современной библиотеки.

В планах на будущее - создание детской игровой комнаты, где можно скоротать время в холодную или мокрую погоду, почитать рукодельную книгу, просто посидеть с комфортом. Настольные игры в дни летних и зимних каникул и сегодня пользуются повышенным спросом. И это прекрасная возможность организации досуга в семье, развития творческих способностей. Приобретение новых, современных гаджетов, электронных игр, ближайшая перспектива для учреждения. И все это с учетом восприятия людей с ограниченными возможностями здоровья.

Сектор выдачи звуковой и брайлевской книги выделен в специальной библиотеке давно. Он обслуживает пользователей регионального центра. Сотрудники всегда помогут с выбором литературы на любой вкус. При этом все могут свободно разговаривать, не мешая проведению групповых занятий, и другим посетителям, занятым работай на компьютере или чтением. Брайлевская литература в больших объемах доставляется на дом читателю автотранспортом.

Сектор внестационарного обслуживания ведет работу по обслуживанию читателей библиотечных пунктов, расположенных в 38 муниципалитетах края, выполняет индивидуальные запросы незрячих пользователей из отдаленной сельской местности, осуществляет надомное обслуживание инвалидов ограниченной мобильности по предварительным заявкам.

В специальной библиотеке работает несколько клубов по интересам и кружков. Группы формируются в зависимости от возраста и категории инвалидности.

Например, клуб «Оптимисты» организован более 10 лет назад для людей с нарушением слуха. Возглавляет его специалист с библиотечным образованием, являющийся инвалидом по слуху. Кроме того, 3 сотрудника учреждения повысили квалификацию на курсах по освоению русского жестового языка и теперь активно применяют его в повседневной работе. Библиотека организует и проводит жестовые конкурсы и викторины, дни жестового чтения о новостях в мире (из периодической печати), создает видеозаписи по юбилейным датам писателей, доступные на официальном сайте и в соцсетях. Участники клуба с удовольствием идут в библиотеку, становятся героями театральных постановок, участвуют в сетевых акциях, сурдоэкскурсиях с выездом на природу или в учреждения культуры, занимаются просмотром и обсуждением фильмов с сурдопереводом и субтитрами.
В будущем планируем установку терминала с индукционной петлей и функционалом для глухих, где сурдопереводчик, рассказывает читателям о библиотеке, её возможностях, услугах, клубах, рекламирует новинки книг, и другое. Аудиогид помог бы людям с нарушением слуха ориентироваться в пространстве без помощи библиотечного работника [3].

Более 30 лет клубу для незрячих людей «Старые друзья», который объединяет людей пожилого возраста. Они постоянные участники краевых конкурсов среди лиц с ограниченными возможностями здоровья, брайлевских турниров и краевых брайлевских чтений, интеллектуальных игр по творчеству писателей, литературномузыкальных вечеров. Несмотря на возраст - они самые начитанные читатели.

Киноклуб «Кино на равных» может посетить любой желающий. В зависимости от набора группы осуществляется демонстрация фильмов с тифлокомментариями или субтитрами. Но эту услугу можно получить и индивидуально.

Огромную помощь в работе с инвалидами оказывают волонтеры. Без них не обходится ни одно крупное мероприятие - фестиваль книги «Издано на Алтае», или Всероссийская акция в поддержку чтения «Библионочь», или межрегиональная или краевая конференция - они помогают не только в качестве сопровождающих, но и сами становятся ведущими мероприятий. Этому сотрудничеству рады наши партнеры - коррекционные образовательные учреждения, краевые общественные организации «Всероссийское общество слепых», «Всероссийской общество глухих», «Всероссийское общество инвалидов», социально-реабилитационные центры, общественные и благотворительные организации, учреждения культуры края, органы социальной защиты населения и другие учреждения. Разве могла библиотека мечтать об этом 20 лет назад?

Расширению спектра услуг для инвалидов во многом способствует проектная деятельность. Благодаря ей ведется издательская деятельность по популяризации творчества алтайских авторов, создаются тактильные книги для маленьких читателей, приобретается новое реабилитационное оборудование, проводятся новые интересные мероприятия, сотрудники повышают свой профессиональный уровень.

Но, главное, и сотрудники библиотеки, и её читатели ждут этих позитивных изменений. Они помогут привлечь в учреждение новых молодых продвинутых пользователей, которые смогут конкурировать на равных со своими сверстниками. 


\section{Список литературы}

1. Об утверждении требований доступности к учреждениям культуры с учетом особых потребностей инвалидов и других маломобильных групп населения : утв. приказом Министерства культуры Российской Федерации от 9 сент. 2015 г. № $2400 . \quad$ URL: https://www.garant.ru/products/ipo/prime/doc/ 71183280/ (15.11.2020).

2. Об утверждении Порядка обеспечения условий доступности для инвалидов библиотек и библиотечного обслуживания в соответствии с законодательством Российской Федерации о со- циальной защите инвалидов : утв. приказом Министерства культуры Российской Федерации от 10 нояб. 2015 г. № 2761. URL: https://www.garant.ru/products/ipo/prime/doc/71183 650/ (11.11.2020).

3. Первая Интернациональная ОнлайнБиблиотека для инвалидов по зрению «Логос»: [сайт].URL: http://av3715.ru/ (22.11.2020).

4. Харламенков A.E. Адаптация глухих и реакция социума // Научные труды Института непрерывного профессионального образования. 2014. № 2. C. 269-273. 